\title{
COLONIZAÇÃO E QUALIDADE DEMOCRÁTICA: APONTAMENTOS COM BASE NO DEMOCRACY INDEX 12
}

\author{
Juliana Zalamena ${ }^{3}$
}

\begin{abstract}
RESUMO
As principais potências europeias empreenderam um dos seus maiores feitos de engenharia social com os processos de colonização de territórios em vários continentes. Esses territórios deram origem a países com características específicas, mas com um ponto em comum: a herança deixada pelo colonizador. Este artigo pretende examinar, com base na classificação dos países conforme seu modelo de administração colonial Indirect Rule ou Direct Rule - e no índice de democracia do jornal The Economist denominado "Democracy Index", em que medida um dos poucos pontos que todos os países aqui considerados têm em comum (ou seja, a colonização) deixou legados na qualidade da sua atual democracia. Supomos que os países colonizados pela Inglaterra, com base no modelo de Indirect Rule, têm maior facilidade em desenvolver seus regimes democráticos, enquanto as ex-colônias de Direct Rule, modelo aplicado pelas demais potências, têm dificuldade em empreender a democracia.
\end{abstract}

Palavras-chave: Colonização. Índice. Democracia. Qualidade.

\section{ABSTRACT}

The major European powers have undertaken one of their greatest deeds of social engineering with the processes of colonization of territories on several continents. These territories gave rise to countries with specific characteristics, but with one point in common: the inheritance left by the colonizer. This article intends to examine, based on the classification of countries according to its model of colonial administration - Indirect Rule or Direct Rule - and in the index of democracy of the magazine The Economist denominated "Democracy Index", to what extent one of the few points that all the countries considered here have in common (that is, colonization) left legacies in the quality of their current democracy. We assume that countries colonized by England, based on the Indirect Rule model, are more likely to develop their democratic regimes, while the former colonies of Direct Rule, a model applied by the other powers, find it difficult to undertake democracy.
\end{abstract}

Keywords: Colonization. Index. Democracy. Quality

\section{RESUMEN}

Las principales potencias europeas emprendieron uno de sus mayores hechos de ingeniería social con los procesos de colonización de territorios en varios continentes. Estos territorios dieron origen a países con características específicas, pero con un punto en común: la herencia dejada por el colonizador. Este artículo pretende examinar, desde la clasificación de los países según su modelo de administración colonial - Indirect Rule o Direct Rule - y en el índice de democracia del diario The Economist denominado "Democracy Index", en qué medida uno de los pocos puntos que todos los países aquí considerados tienen en común (es decir, la colonización) dejó legados en la calidad de su actual democracia. Suponemos que los países colonizados por Inglaterra, con base en el modelo de Indirect Rule, tienen mayor facilidad en desarrollar sus regímenes democráticos, mientras que las ex colonias de Direct Rule, modelo aplicado por las demás potencias, tienen dificultad en emprender la democracia.

Palabras clave: Colonización. Índice. Democracia. Calidad.

\section{INTRODUÇÃO}

Dos 165 países e 2 territórios cuja democracia é examinada no Democracy Index, índice desenvolvido e divulgado pelo jornal The Economist, 95 foram colonizados por

\footnotetext{
${ }^{1}$ Enviado: 12/08/2017. Aceito: 05/12/2017.

${ }^{2}$ DOI: http://dx.doi.org/10.5380/recp.v9i1.54493

${ }^{3}$ Assistente social, Socióloga e Mestre em Ciência Política (UFRGS). E-mail: zalamenajuliana5@gmail.com
} 
ZALAMENA, J. C. M. Colonização e qualidade democrática: apontamentos com base no democracy index

potências europeias em algum momento da sua história. Embora tenham sido Portugal e Espanha os primeiros a empreender as chamadas "Grandes Navegações", ficando com o mérito dos tão celebrados e conhecidos "descobrimentos", também a Inglaterra, a França, a Bélgica e até mesmo a recém-unificada Itália quiseram o seu quinhão dos chamados “impérios coloniais". Foi assim que o mundo acabou dividido, numa visão simplista, em "colonizados" e "colonizadores". Obviamente, existem nações que não foram diretamente afetadas por este processo e que nunca colonizaram nem mesmo foram colonizadas. Porém, para este trabalho, interessa um grupo específico: aquele das nações que um dia foram colonizadas por potências europeias.

Tal colonização ocorreu num espaço de tempo vasto: desde os anos 1500 , quando os primeiros navegadores se apropriaram dos primeiros territórios invadidos por europeus, até as décadas posteriores à Segunda Guerra Mundial, quando as últimas colônias foram desocupadas. O tempo de independência desses países varia muito, sendo que os últimos a se tornarem independentes de suas metrópoles eram, em maior parte, países africanos. O certo é que, nesse período, os colonizadores deixaram muitas heranças aos colonizados, as quais, além da economia, da sociedade e da cultura, também envolvem a política. ${ }^{4}$

Apesar de tal legado ser vasto, o que nos interessa especificamente é o modelo de administração colonial aplicado pelas potências europeias, o qual pode ser dividido em "Indirect Rule" — desenvolvido e posto em prática pela Inglaterra — e "Direct Rule" — disseminado pela França e pelas demais potências colonizadoras. Evidentemente, tais modelos não foram aplicados de maneira idêntica por todas as potências, nem sequer aplicados da mesma forma pela mesma potência em todos os territórios por ela colonizados. O detalhamento da conceituação de ambos os modelos e também a sua aplicação nos mais diferentes territórios foi brevemente abordado no item que trata dos conceitos aqui utilizados e do caminho metodológico aqui adotado, assim como o entendimento sobre democracia que orienta a classificação do Democracy Index.

A metodologia utilizada neste artigo é simples: trata-se da análise dos 95 países colonizados e abordados pelo Democracy Index com base no seu modelo de colonização e na sua classificação no índice. Chamamos atenção para o fato de que a simples verificação de frequência não possui a capacidade de avaliar a relação entre colonização e qualidade da democracia, embora tais resultados possam representar um índice razoável de caráter

\footnotetext{
${ }^{4}$ Este trabalho representa um recorte de uma pesquisa maior, que verifica estatisticamente a relação da colonização com a qualidade da democracia dos países colonizados e inclui outros fatores além da classificação do Democracy Index.
} 
exploratório. A hipótese que orienta o trabalho é a de que os países colonizados pela Inglaterra, cujo modelo de administração foi o Indirect Rule, possuem maior facilidade de desenvolver seus regimes democráticos, enquanto aqueles colonizados pela França e demais potências, a partir do modelo de Direct Rule, encontram mais dificuldade em desenvolver e consolidar suas democracias.

Sendo modesto o escopo deste trabalho, os resultados da análise aqui apresentada não podem ser considerados taxativos no que diz respeito à influência da colonização sobre a qualidade da democracia. Assim, o objetivo, aqui, é definir e relatar em que modelo Indirect ou Direct Rule - as ex-colônias analisadas obtiveram melhor resultado na classificação do Democracy Index. Para estabelecer padrões verificáveis - dentro de uma análise estatística —, visando comprovar a influência dos modelos de administração colonial na qualidade democrática das ex-colônias, seria necessário incluir na pesquisa outros fatores e testá-los através de métodos mais complexos, o que foge do intento mencionado.

Os resultados da análise estão dispostos no item "Resultados e discussão", no qual buscamos detalhar os dados obtidos e traçar apontamentos sobre a influência do modelo de administração colonial nos atuais regimes de governo das ex-colônias, especialmente no que tange à democracia. Por fim, as considerações finais do trabalho nos sugerem que o fator “colonização", isoladamente, não é suficiente para explicar o desenvolvimento e a qualidade da democracia, apesar de os seus resultados sugerirem que existe uma influência notável do modelo de colonização na qualidade democrática das ex-colônias.

\section{CONCEITOS E CAMINHO METODOLÓGICO}

Os conceitos elencados para este trabalho são simples: de um lado, a qualidade da democracia e, de outro, o modelo de colonização, no que diz respeito à administração colonial. Porém, é necessário explicar algumas opções que podem ser feitas. Facilmente encontramos, inclusive nos livros de História e Geografia do Ensino Fundamental, a noção da colonização dividida em "povoamento" e "exploração", sendo que a tese mais difundida é a de que as colônias de povoamento se desenvolveram e se tornaram nações bem-sucedidas social, política e economicamente, enquanto as colônias de exploração geraram países problemáticos e com muitas dificuldades para se desenvolver (MONASTERIO e EHRL, 2015). ${ }^{5}$ Essa concepção é reducionista e não dá conta de explicar as muitas especificidades da

\footnotetext{
${ }^{5}$ Essa concepção tem origem remota. Monasterio e Ehrl (2015) realizaram um mapeamento das origens da concepção de que colônias de povoamento geraram países desenvolvidos e colônias de exploração geraram
} 
ZALAMENA, J. C. M. Colonização e qualidade democrática: apontamentos com base no democracy index

colonização, além de obviamente favorecer a Inglaterra e seu modelo de colonização de povoamento (ALMEIDA, 2010).

Partimos do pressuposto de que o objetivo da colonização — seja lá qual a potência que o tenha operacionalizado - é o lucro. Trata-se de utilizar aquele território colonizado em proveito econômico da metrópole (SOUZA, 2008). Destarte, em nenhuma das potências o processo se deu de maneira diferente. Além disso, simplesmente não se pode explorar uma colônia sem um certo grau de povoamento, e muito menos povoar sem nenhuma exploração. Portanto, todas as colônias tiveram um grau maior ou menor de exploração e de povoamento, concomitantemente. Assim, para avaliar a influência do processo colonizador no desenvolvimento da democracia, não nos parece adequado adotar tal distinção. Além disso, o continente africano tem suas especificidades: mesmo os países colonizados pela Inglaterra autointitulada precursora da colonização de povoamento — foram colônias totalmente voltadas para a exploração.

Dados esses problemas de definição quanto à colonização de exploração e de povoamento, adotamos a distinção entre os processos colonizadores com base no modelo de administração colonial adotado, ou seja, de Indirect Rule e de Direct Rule. Essa conceituação está baseada principalmente nos trabalhos de Gerring et al. (2011), Banerjee e Iyer (2005) e Iyer (2010). O primeiro foi adotado pela Inglaterra e se refere basicamente à prática de incluir chefes e líderes locais na administração da colônia, enquanto o segundo, que foi disseminado pela França e aplicado pelas demais potências, pressupõe a exclusão completa das lideranças locais, com a administração da colônia sendo feita apenas por colonos europeus migrantes (MABEKO-TALI, 2013; GERRING et al., 2011). Assim,

[...] o Direct Rule ou a administração direta francesa, que visa à assimilação dos povos colonizados dentro do modelo racista universalista destruidor das identidades não-ocidentais, por outro o Indirect Rule ou a administração indireta britânica, que visa à aculturação dos povos colonizados, num processo que declaradamente pretendia conservar as identidades tradicionais para não criar choques desnecessários que poderiam prejudicar o processo aculturativo. (MUNANGA, 2005-2006, p. 49-50).

Para um entendimento mais detalhado de tais conceitos, recorremos a Doyle (1986), que defende que o modelo de Indirect Rule foi a forma de administração colonial adotada pela Inglaterra para controlar seus impérios coloniais, de modo a aproveitar as estruturas de poder locais, enquanto o Direct Rule teria estabelecido uma autoridade estrangeira centralizada 
dentro dos territórios, gerida por indivíduos vindos da metrópole especialmente para este fim. Tais modelos não são rígidos e inflexíveis, tampouco aplicados de forma idêntica por todas as potências europeias em todos os seus territórios coloniais. Os estudos de Iyer (2010) e Banerjee e Iyer $(2005)^{6}$ apontam que os territórios cujo domínio cultural foi indireto (Indirect Rule), que basicamente se encontravam sob administração dos reis indianos ao invés da Coroa Britânica, embora subordinados a esta última, apresentaram maior desenvolvimento póscolonial do que áreas cujo domínio colonial era direto (Direct Rule). Ambos os estudos demonstram a persistência das heranças das instituições impostas no período colonial, fornecendo pistas de que elementos históricos importam no sucesso ou fracasso da democracia, estando entre eles a prevalência do modelo de governo parlamentarista nas excolônias inglesas e, nas demais, a do presidencialismo ou semipresidencialismo. ${ }^{7}$ Podemos ainda mencionar a incidência do chamado "Socialismo Africano", ou seja, a implementação de regimes inspirados na União Soviética adaptados para a realidade do continente africano nos países colonizados por Portugal (MELLO, 2016), como foi o caso de Moçambique. Outro destaque em relação à Inglaterra fica por conta da inclusão dos países recém-independentes na Commonwealth. ${ }^{8}$

Portugal, por exemplo, teve administrações coloniais diferentes no que diz respeito ao Brasil, aos territórios do continente africano (Angola, Moçambique e Guiné-Bissau) e, ainda, às ilhas (São Tomé e Príncipe e Cabo Verde), bem como a Inglaterra adaptou suas estratégias e seu modelo de Indirect Rule de acordo com as especificidades e características próprias de cada território colonizado - o que pode-se verificar a olho nu se compararmos as diferenças entre ex-colônias americanas, africanas e asiáticas colonizadas pelos britânicos. Assim, o trabalho não pretende afirmar que os modelos foram aplicados de forma homogênea, mas adotamos uma classificação simples, por conta das limitações do modesto escopo deste trabalho. Ambos os modelos foram aplicados com diferenças conforme as especificidades de cada colônia e, quando aqui se lê "ex-colônias de Indirect Rule" ou "ex-colônias de Direct Rule", estamos assumindo que, em termos generalistas, esta foi a orientação predominante do modelo de administração colonial.

\footnotetext{
${ }^{6}$ A territorialidade de ambos os estudos é a Índia.

${ }^{7}$ Dentre os inúmeros trabalhos que mencionam países parlamentaristas, presidencialistas e semipresidencialistas, podemos elencar os de Stepan (1990), Valenzuela (1991), Batista (2016) e, principalmente, Mainwaring (1990, 1993)

8 Comunidade britânica de nações de alguma forma associadas à soberania inglesa (LACOSTE; RAJAGOPALAN, 2005) “[...] que mantém, até nossos dias, estreitos laços culturais, econômicos e políticos com o Reino Unido" (PASSETI, 2016, p. 24).
} 
ZALAMENA, J. C. M. Colonização e qualidade democrática: apontamentos com base no democracy index

Supõe-se que os países que foram ex-colônias inglesas de Indirect Rule tiveram, durante seu período como subordinados à Inglaterra, uma experiência muito próxima do selfgovernment aplicado nos Estados Unidos e, por isso, acumularam alguma capacidade de autogestão. Tais países, com uma experiência mais ampla em se autogovernar, podem ter adquirido uma propensão maior a desenvolver seus regimes democráticos com sucesso. Enquanto isso, aqueles países que foram ex-colônias de Direct Rule, por terem passado todo o período colonial relegados à administração externa, sem nenhuma autogovernação, possuiriam maiores dificuldades nesse campo.

A partir dessa classificação das ex-colônias, temos 38 países colonizados dentro do modelo inglês de Indirect Rule e 57 países colonizados dentro do modelo de Direct Rule, os quais estiveram em posse da Espanha, da França, de Portugal, da Itália e da Bélgica, somando-se então, ao todo, 95 dos 167 territórios analisados pelo Democracy Index. Este índice, elaborado pelo jornal The Economist, pretende mensurar a qualidade democrática dos países e classificá-los em: 1) Democracias completas; 2) democracias defeituosas; 3) Regimes híbridos; e 4) Regimes autoritários. Os critérios para mensurar a qualidade democrática estão longe de ser um consenso dentro da Ciência Política e de outras áreas afins, mas o Democracy Index, especificamente, utiliza cinco quesitos no que diz respeito a essa questão: a) processo eleitoral e pluralismo; b) funcionamento do governo; c) participação política; d) cultura política; e e) liberdades civis.

Conceituar a democracia é um procedimento árduo, difícil e, provavelmente, pouco consensual. Etimologicamente, temos para o termo o significado de "governo do povo" e, historicamente, temos a experiência da democracia direta da Grécia Antiga, na qual todos os cidadãos participavam do processo decisório, processo este que só era possível devido ao número diminuto de pessoas consideradas cidadãs e aos limites territoriais limitados. Atualmente, a democracia direta é impossível, e a melhor opção para operacionalizá-la em países com grandes territórios, grandes populações e cidadania ampliada passou a ser a democracia representativa, na qual os eleitores escolhem seus representantes, os quais, quando eleitos, têm o poder de decidir por eles.

As teorias minimalistas (SCHUMPETER, 1984; PRZEWORSKI, 1999) defendem que podemos entender como "democracias" os sistemas políticos em que a competição política acontece através do voto. Temos aí uma centralidade pronunciada na questão da existência de eleições livres, justas e periódicas. Através das eleições, o cidadão escolhe seus representantes, mediante a concordância de seus interesses e as propostas do candidato/partido (PRZEWORSKI, 1999). Em sua classificação de democracia, Przeworski et 
al. (1997, p. 131) nos dizem que ela é "[...] um regime no qual os cargos governamentais são preenchidos em consequência de eleições competitivas". Além disso, de acordo com os autores, “[...] um regime é democrático somente se a oposição estiver autorizada a competir, vencer e tomar posse dos cargos". Obviamente, essa é uma definição minimalista, mas as eleições e a competição são critérios básicos nos quais qualquer democracia se alicerça. A partir daí, surgem outros critérios que vão aumentando a qualidade da democracia e a sua solidificação.

Em seu trabalho, Manin, Przeworski e Stokes (2006) pretenderam estabelecer o quanto o mecanismo eleitoral torna as instituições democráticas mais representativas. De acordo com eles, “[...] na democracia os governos são representativos porque são eleitos: se as eleições são concorridas livremente, se a participação é ampla, e se os cidadãos desfrutam das liberdades políticas, então os governos agirão em favor do interesse da população" (MANIN; PRZEWORSKI; STOKES, 2006, p. 105). Porém, a democracia não depende única e exclusivamente do fator "eleição" para sobreviver, uma vez que muitos outros fatores interferem na sua qualidade.

Przeworski et al. (1997, p. 113) entendem que, para construir e manter um regime democrático, uma nação precisa possuir "[...] riqueza, crescimento com inflação moderada, desigualdade decrescente, um clima internacional favorável e instituições parlamentaristas" - ou seja, condições que extrapolam os critérios elencados pelo Democracy Index, principalmente no que diz respeito aos fatores econômicos que influenciam a democracia, os quais são negligenciados pelo ranking.

Uma das principais críticas feitas ao Democracy Index diz respeito à ausência de critérios econômicos na sua avaliação das democracias. Sobre isso, vários autores sustentam os argumentos de que as democracias são extremamente frágeis em países pobres (HUNTINGTON, 1975; O’DONNEL, 1973; LIPSET, 1959) e de que quanto menor a intensidade dos conflitos em torno da distribuição de renda, maior a durabilidade e qualidade da democracia. Diamond e Linz (1989) concordam, de certa forma, com esse argumento, dizendo que as crises econômicas representam uma das maiores ameaças à estabilidade dos regimes democráticos, assim como Hirschmann (1981) diz que uma taxa de inflação moderada permite que os governos pacifiquem com sucesso os grupos militantes.

Outro fator de manutenção da democracia é o clima internacional favorável, conforme o entendimento de Przeworski et al. (1997). Em tese, quanto maior o número de democracias no entorno de um determinado país, maior a probabilidade de que este comece a caminhar nos rumos democráticos. Esse fator, considerando-se aqui os problemas 
ZALAMENA, J. C. M. Colonização e qualidade democrática: apontamentos com base no democracy index

metodológicos dessa mensuração, também não é observado no ranking do Democracy Index. Além disso, os autores ainda nos lembram da relevância do "aprendizado político", ou seja, da ideia de que quanto maiores as tradições democráticas dentro de um país, maior a permanência e solidificação da democracia no seu território.

Dahl (1997), por exemplo, acredita que não existe, no mundo atual, nenhuma democracia perfeita. O autor elaborou uma classificação baseada em hegemonias fechadas, hegemonias inclusivas, oligarquias competitivas e poliarquias, sendo estas últimas as mais próximas de um modelo ideal de democracia. A possibilidade de vários graus de democracia foi adotada por vários índices, inclusive pelo Democracy Index. De qualquer modo, como nos lembram Przeworski et al. (1997, p. 121), as “[...] democracias não são todas iguais”. As instituições e configurações de um regime democrático variam amplamente, de modo que a mensuração em torno de critérios gerais dificilmente terá resultados inquestionáveis. Em outras palavras, um determinado comportamento pode favorecer uma democracia e, ao mesmo tempo, desfavorecer outra.

Por isso, o ranking do Democracy Index não pode ser considerado uma fotografia fiel da realidade dos países analisados. Porém, ainda assim, sua abrangência é notável e os critérios eleitos para mensurar a qualidade democrática nas nações são amplos. Além disso, deve-se considerar a sua credibilidade perante os ambientes acadêmicos e midiáticos. Não se trata de um ranking com uma confiabilidade inquestionável, mas é uma boa fonte de dados para a nossa comparação.

Para tentar comprovar nossa hipótese — de que ex-colônias de Indirect Rule têm maiores condições de efetivar suas democracias, enquanto ex-colônias de Direct Rule possuem um legado de instabilidade e fragilidade democrática no seu pós-independência —, cruzamos a nossa classificação, conforme o modelo de administração colonial, com a pontuação geral do Democracy Index, bem como com seus cinco critérios separadamente. O próximo item trata dos resultados obtidos e da discussão dos mesmos com base nas teorias democráticas selecionadas.

\section{RESULTADOS E DISCUSSÃO}

O Democracy Index fornece um apanhado geral do estado das democracias de 165 estados independentes e 2 territórios, o que inclui praticamente toda a população mundial. Apesar de muito utilizado pela mídia e pelo ambiente acadêmico em geral, tal índice recebe muitas críticas. Portanto, a análise a seguir não tem a pretensão de observar padrões 
inegáveis, mas de sugerir ideias gerais no que diz respeito à relação entre o modelo de administração colonial e a qualidade da democracia. Embora diversos países possam ser considerados democráticos, o número de democracias completas é muito baixo: era 28 em 2006 e, agora, dez anos depois, caiu para 19. No relatório de 2016, o quadro das classificações era assim constituído:

TABELA 1

\begin{tabular}{|c|c|c|c|c|}
\hline Tipos de regime & Pontuação & $\begin{array}{c}\text { Número de } \\
\text { países }\end{array}$ & $\begin{array}{c}\text { Percentual de } \\
\text { países }\end{array}$ & $\begin{array}{c}\text { Percentual da } \\
\text { população } \\
\text { mundial }\end{array}$ \\
\hline $\begin{array}{c}\text { Democracias } \\
\text { completas }\end{array}$ & $8 \leq \mathrm{s} \leq 10$ & 19 & 11,4 & 4,5 \\
\hline $\begin{array}{c}\text { Democracias } \\
\text { defeituosas }\end{array}$ & $6 \leq \mathrm{s}<8$ & 57 & 34,1 & 44,8 \\
\hline Regimes híbridos & $4 \leq \mathrm{s}<6$ & 40 & 24 & 18 \\
\hline $\begin{array}{c}\text { Regimes } \\
\text { autoritários }\end{array}$ & $0 \leq \mathrm{s}<4$ & 51 & 30,5 & 32,7 \\
\hline
\end{tabular}

FONTE: Adaptado de THE ECONOMIST (2016).

O número baixo de democracias completas é compensado por uma quantidade satisfatória de democracias defeituosas, em 57 países, os quais, apesar de terem alguns problemas, ainda podem ser classificadas como democráticos e livres. Dos restantes, 40 são considerados regimes híbridos e 51 apresentam regimes autoritários. De acordo com a mensuração do índice, $32,7 \%$ da população mundial — com referência no ano de 2016 — ainda vive em regimes ditatoriais.

A situação por região, no ano de 2016, demonstra que os países da América do Norte e da Europa Ocidental dominam o topo da lista, enquanto o Oriente Médio e o norte da África apresentam a pior situação. As democracias completas estão concentradas na Europa Ocidental - Noruega, Islândia, Suécia, Nova Zelândia, Dinamarca, Irlanda, Suíça, Finlândia, Luxemburgo, Holanda, Alemanha, Áustria, Malta, Reino Unido e Espanha -, com poucas exceções, que se constituem em Canadá, único representante da América do Norte, Austrália, país da Oceania, Maurícia, único país da África Subsaariana a obter um conceito alto no índice, e Uruguai, único representante da América do Sul nessa lista. Na tabela abaixo, montamos a classificação geral do Democracy Index: 
ZALAMENA, J. C. M. Colonização e qualidade democrática: apontamentos com base no democracy index

TABELA 2

\begin{tabular}{|c|c|c|c|}
\hline Democracias completas & Democracias defeituosas & Regimes híbridos & Regimes autoritários \\
\hline $\begin{array}{l}\text { Noruega, Islândia, } \\
\text { Suécia, Nova Zelândia, } \\
\text { Dinamarca, Canadá, } \\
\text { Irlanda, Suíça, Finlândia, } \\
\text { Austrália, Luxemburgo, } \\
\text { Holanda, Alemanha, } \\
\text { Áustria, Malta, Reino } \\
\text { Unido, Espanha, } \\
\text { Maurícia e Uruguai }\end{array}$ & $\begin{array}{l}\text { Japão, Estados Unidos, } \\
\text { Itália, Cabo Verde, França, } \\
\text { Coreia do Sul, Costa Rica, } \\
\text { Botswana, Portugal, Israel, } \\
\text { Estônia, República Checa, } \\
\text { Índia, Taiwan, Chile, } \\
\text { Bélgica, Chipre, Eslovênia, } \\
\text { Lituânia, África do Sul, } \\
\text { Jamaica, Letônia, } \\
\text { Eslováquia, Timor-Leste, } \\
\text { Grécia, Panamá, Trinidad e } \\
\text { Tobago, Bulgária, Indonésia, } \\
\text { Argentina, Filipinas, Brasil, } \\
\text { Polônia, Suriname, Croácia, } \\
\text { Gana, Hungria, República } \\
\text { Dominicana, Colômbia, } \\
\text { Peru, El Salvador, Romênia, } \\
\text { Mongólia, Lesoto, Sérvia, } \\
\text { Malásia, Sri Lanka, México, } \\
\text { Hong Kong, Tunísia, } \\
\text { Singapura, Namíbia, } \\
\text { Paraguai, Guiana, Senegal, } \\
\text { Papua-Nova Guiné e } \\
\text { Moldávia }\end{array}$ & $\begin{array}{l}\text { Zâmbia, Geórgia, } \\
\text { Honduras, Guatemala, } \\
\text { Albânia, Equador, } \\
\text { Tanzânia, Bangladesh, } \\
\text { Montenegro, Ucrânia, } \\
\text { Mali, Benin, Fiji, } \\
\text { Bolívia, Malawi, } \\
\text { Quênia, Libéria, } \\
\text { Uganda, Macedônia, } \\
\text { Madagascar, Turquia, } \\
\text { Quirguistão, Butão, } \\
\text { Tailândia, Bósnia } \\
\text { Herzegovina, Líbano, } \\
\text { Nepal, Nicarágua, } \\
\text { Marrocos, Burkina } \\
\text { Faso, Venezuela, Serra } \\
\text { Leoa, Nigéria, } \\
\text { Palestina, Paquistão, } \\
\text { Camboja, Myanmar, } \\
\text { Iraque, Moçambique e } \\
\text { Haiti }\end{array}$ & $\begin{array}{l}\text { Mauritânia, Jordânia, } \\
\text { Níger, Armênia, } \\
\text { Kuwait, Costa do } \\
\text { Marfim, Gabão, } \\
\text { Comores, Etiópia, } \\
\text { Argélia, Belarus, } \\
\text { Camarões, Cuba, } \\
\text { Angola, Vietnã, Togo, } \\
\text { Egito, Rússia, Qatar, } \\
\text { China, Guiné, Ruanda, } \\
\text { Cazaquistão, } \\
\text { Zimbábue, Omã, } \\
\text { Suazilândia, República } \\
\text { do Congo, Gâmbia, } \\
\text { Djibouti, Barein, } \\
\text { Emirados Árabes } \\
\text { Unidos, Azerbaijão, } \\
\text { Afeganistão, Burundi, } \\
\text { Sudão, Eritréia, Laos, } \\
\text { Iran, Líbia, Iêmen, } \\
\text { Guiné-Bissau, } \\
\text { Uzbequistão, } \\
\text { República Democrática } \\
\text { do Congo, Arábia } \\
\text { Saudita, Tajiquistão, } \\
\text { Turcomenistão, Guiné } \\
\text { Equatorial, República } \\
\text { Centro-Africana, } \\
\text { Chade, Síria e Coreia } \\
\text { do Norte. }\end{array}$ \\
\hline
\end{tabular}

FONTE: Adaptado de THE ECONOMIST (2016).

Desde que o The Economist começou a divulgar o Ranking, a Ásia fez mais progresso do que qualquer outra região, aumentando sua média regional de 5,44, em 2006, para 5,74, em 2016. No entanto, apesar dos progressos na última década, a região ainda está longe de superar a América Latina $(6,33)$, a Europa Ocidental $(8,40)$ e a América do Norte $(8,56)$. Já a Europa viu despencar seu número de democracias completas na última década. $\mathrm{O}$ progresso democrático na África teve sutis melhoras na participação política e na cultura política, mas as pontuações sobre liberdades civis e funcionamento de governo caíram. Ainda que as eleições tenham se tornado comuns na maioria dos países da região, a pontuação no quesito de processo eleitoral e pluralismo continuou baixa, refletindo eleições que ficam concentradas no aspecto formal, não funcionando na prática, e também na ausência de um pluralismo genuíno.

De acordo com a nossa classificação, dos 167 países/territórios que o Democracy Index abrange, 95 foram colonizados por uma potência europeia em algum momento da 
corrida pelos impérios coloniais. A partir da classificação das ex-colônias inglesas como de Indirect Rule e as demais ex-colônias como de Direct Rule, obtivemos a seguinte tabela:

TABELA 3

\begin{tabular}{|c|c|c|c|}
\hline \multirow{2}{*}{$\begin{array}{c}\text { Classificação } \\
\text { Democracy Index }\end{array}$} & \multicolumn{3}{|c|}{ Modelo de administração colonial (\%) } \\
\cline { 2 - 4 } & Total & Direct Rule & Indirect Rule \\
\hline Total & $\mathbf{9 5}$ & $\mathbf{5 7}$ & $\mathbf{3 8}$ \\
\hline Democracia completa & 5 & $1,0 \%$ & $4,2 \%$ \\
\hline Democracia defeituosa & 30 & $17,8 \%$ & $13,6 \%$ \\
\hline Regime híbrido & 26 & $14,7 \%$ & $12,6 \%$ \\
\hline Regime autoritário & 34 & $26,3 \%$ & $9,4 \%$ \\
\hline
\end{tabular}

FONTE: Adaptado de THE ECONOMIST (2016).

Embora o continente africano tenha sido praticamente todo tomado pelos europeus, a Etiópia, a Libéria e a Namíbia se constituem em notáveis exceções no padrão geral do continente, tendo os três países histórias bastante peculiares. A Etiópia jamais foi colonizada, tendo repelido com sucesso as tropas italianas que pretendiam dominá-la (BARKER, 1979; AKPAN, 2010a, 2010b; PÁEZ, 1945). A Libéria também não foi colonizada, mas foi um território literalmente comprado pelos Estados Unidos para enviar seus escravos libertos (ARANHA, 2004), enquanto a Namíbia, que foi praticamente propriedade particular do empresário Cecil Rhodes, passando de colônia alemã para o domínio da Liga das Nações e, depois, para a África do Sul, foi uma das últimas nações do continente africano a se tornar livre, em 1990 (CORREA, 2014; PINI, 2014). Por esse motivo, a Libéria e a Etiópia não estão elencadas entre os países analisados aqui, pois não representam ex-colônias. A Namíbia, embora também não tenha seguido o mesmo caminho da maioria dos países africanos, tem uma ligação histórica com a Inglaterra e, por isso, foi classificada como uma ex-colônia inglesa. Outras ex-colônias, como é o caso de São Tomé e Príncipe, não estão elencadas dentre os países analisados pelo Democracy Index.

Dentre os 95 países colonizados, os governos de apenas 5 países são considerados democracias completas, sendo que a Nova Zelândia, o Canadá, a Austrália e a Maurícia são ex-colônias inglesas de Indirect Rule. O Uruguai é uma notável exceção no que diz respeito a esse quesito, constituindo-se em uma democracia completa mesmo tendo sido uma colônia espanhola de Direct Rule. Aparentemente, embora muito sutilmente, esse é um dado favorável à comprovação da hipótese deste artigo. Porém, como as democracias completas são poucas, nossa análise fica limitada - apesar de os dados apontarem que 4,2\% das democracias completas foram colônias de Indirect Rule, enquanto apenas 1\% foi de Direct Rule. Este último também deu origem à maior parte dos regimes autoritários (26,3\%). Assim, 
ZALAMENA, J. C. M. Colonização e qualidade democrática: apontamentos com base no democracy index

embora nossos dados não possam nos dizer claramente que as colônias de Indirect Rule acabaram por ter melhor desempenho democrático, eles nos dão a certeza de que as colônias de Direct Rule estão numa situação muito pior.

Temos, portanto, quatro ex-colônias inglesas consideradas democracias completas. Para que nossa hipótese fosse incontestavelmente comprovada, esse número teria, evidentemente, que ser maior. Dentre as demais ex-colônias de Indirect Rule, temos 13 democracias defeituosas, 12 regimes híbridos e, por fim, aqueles regimes que não são considerados democráticos — os regimes autoritários —, que somaram 9 países. Em termos gerais, temos 29 países de legado colonial inglês com o modelo de administração colonial indireto que podem ser considerados democráticos, muito embora 25 deles contenham sérios problemas. Já em termos numéricos, dentre os 57 países de Direct Rule abordados pelo Democracy Index, temos 32 países que podem ser considerados democráticos, dos quais 31 apresentam sérios problemas e 26 têm regimes autoritários. Proporcionalmente, percebemos que as ex-colônias de Direct Rule têm maiores dificuldades para implementar/manter uma democracia. Ainda que de modo sutil, as ex-colônias inglesas apresentam um melhor desempenho a esse respeito.

Um fato bem nítido é o de que embora as colônias de Direct Rule ligadas à França, à Holanda, a Portugal e à Espanha, tenham conseguido desempenhos democráticos razoáveis, a Bélgica e a Itália deixaram, em todos os casos, legados de regimes autoritários, nos casos de Burundi, da República Democrática do Congo e de Ruanda, bem como da Líbia e da Eritreia. Por ser a potência que disseminou o Direct Rule que colonizou mais territórios, a maior parte dos regimes autoritários de hoje é formada por ex-colônias francesas. Podemos dizer que, em termos de herança política, a França deixou um rastro de insucesso em suas colônias.

A literatura que trata do tema da "colonização" é quase sempre favorável à Inglaterra. Através dessas leituras, dá-se a entender que os ingleses colocaram em prática uma colonização mais leve, no sentido de que suas colônias na América do Norte se desenvolveram com ininterrupto sucesso, empregando-se neste continente um modelo de colonização entendido como "de povoamento", e de que aplicou-se um self-government ("autogoverno") nos demais continentes (o qual se aproxima muito do modelo de Indirect Rule). Além disso, tendo sido a primeira potência europeia a se retirar das colônias tardias logo após a Segunda Guerra Mundial, sem passar por processos desgastantes com guerras pela independência, negociando com as colônias pacificamente e, inclusive, trazendo muitas de suas antigas colônias para a Commonwealth, há uma série de motivos pelos quais os países que foram colônias inglesas apresentam um desempenho melhor em termos gerais, inclusive 
no aspecto concernente à democracia. São vários os fatores que favorecem as ex-colônias inglesas, embora nem todas possam ser analisadas por este artigo. Para maiores informações nesse sentido - a respeito da tese "colônia de povoamento" versus "colônia de exploração" —, é possível consultar diversos trabalhos renomados (HEEREN, 1817; PRADO JUNIOR, 1957; ROSCHER, 1856; LEROY-BEAULIEU, 1902; NORTH, 1959; BALDWIN, 1956; ENGERMAN; SOKOLOFF, 1997; ACEMOGLU; JOHNSON; ROBINSON, 2001, 2002).

Peculiaridades várias serão excluídas da nossa análise devido aos limites deste trabalho, como as diferenças entre as colônias portuguesas e espanholas na América e na África - uma vez que as colônias espanholas na América se tornaram independentes muito antes das africanas e têm um desempenho significativamente melhor em relação a elas —, as diferenças econômicas entre os países, as diferenças de tempo de independência dos países (no caso, as colônias americanas se emanciparam ainda no século XIX) e, principalmente, as diferenças entre as aplicações dos modelos de administração colonial pela mesma potência, como entre o comportamento administrativo de Portugal em relação ao Brasil, aos países do continente africano e aos países insulares.

Os cinco critérios do Democracy Index analisados separadamente também parecem fornecer um quadro mais otimista para as ex-colônias de Indirect Rule. Vejamos o primeiro critério, "processo eleitoral e pluralismo", na tabela abaixo:

TABELA 4

\begin{tabular}{|c|c|c|c|c|}
\hline \multirow{2}{*}{$\begin{array}{c}\text { Classificação Democracy Index } \\
\text { processo eleitoral e pluralismo }\end{array}$} & \multicolumn{3}{c|}{ Modelo de administração colonial (\%) } \\
\cline { 2 - 5 } Total & Total & Indirect Rule & Direct Rule \\
\hline \multicolumn{2}{|c|}{} & $\mathbf{9 5}$ & $\mathbf{3 8}$ & $\mathbf{5 7}$ \\
\hline $\begin{array}{c}\text { Democracia } \\
\text { completa }\end{array}$ & $\mathbf{8} \leq \mathbf{s} \leq \mathbf{1 0}$ & 23 & $9,4 \%$ & $14,7 \%$ \\
\hline $\begin{array}{c}\text { Democracia } \\
\text { defeituosa }\end{array}$ & $\mathbf{6} \leq \mathbf{s}<\mathbf{8}$ & 23 & $13,6 \%$ & $10,5 \%$ \\
\hline $\begin{array}{c}\text { Regime } \\
\text { híbrido }\end{array}$ & $\mathbf{4} \leq \mathbf{s}<\mathbf{6}$ & 15 & $5,2 \%$ & $10,5 \%$ \\
\hline $\begin{array}{c}\text { Regime } \\
\text { autoritário }\end{array}$ & $\mathbf{0} \leq \mathbf{s}<\mathbf{4}$ & 34 & $11,5 \%$ & $24,2 \%$ \\
\hline
\end{tabular}

FONTE: Adaptado de THE ECONOMIST (2016).

Como foi elucidado no item especifico sobre os conceitos aqui utilizados, as eleições são um ponto crucial para a análise de uma democracia. As teorias, sejam elas minimalistas ou mais amplas, não deixam de dar uma importância de maior ou menor grau para o processo eleitoral na construção, estabilidade e durabilidade de um regime democrático. Sendo assim, a maioria dos índices que procuram mensurar a qualidade democrática de um país utilizam as 
ZALAMENA, J. C. M. Colonização e qualidade democrática: apontamentos com base no democracy index

eleições como um dos fatores-chave a esse respeito. Embora esse não seja o único critério para medir a qualidade democrática de um país, não se pode negar que o processo de escolha é um dos alicerces fundamentais da democracia. No Democracy Index, o processo eleitoral vem agregado ao conceito de pluralismo, ou seja, não basta apenas a existência das eleições: estas precisam ser inclusivas.

Os dados a esse respeito são um tanto quanto nebulosos. Embora 9,4\% das notas mais altas — de 8 a 10 - a esse respeito sejam de Indirect Rule, temos 14,7\% de ex-colônias de Direct Rule em tal posição. Portanto, não podemos dizer que as ex-colônias inglesas possuem um desempenho muito favorável em relação às demais no que tange ao processo eleitoral e ao pluralismo. Porém, quando somamos as notas correspondentes ao que o índice considera "democracias completas" às das chamadas democracias "problemáticas" (democracias defeituosas e regimes híbridos, com as notas de 4 a 8), o quadro muda sensivelmente: $28,2 \%$ das ex-colônias de Indirect Rule têm notas atribuídas entre 4 e 10, embora algumas tenham sérios defeitos, e apenas 11,5\% obtiveram notas menores que 4. Transformando isso em conceitos do Democracy Index, no caso das demais ex-colônias de Direct Rule, 35,7\% são democracias (4 a 10), enquanto 24,2\% são regimes autoritários (nota menor que 4). Como em termos de números temos 57 países que foram colônias de Direct Rule contra 38 países que foram colônias de Indirect Rule, temos uma margem razoável de diferença a se considerar.

Quanto a esse critério, os dados são sugestivamente favoráveis às ex-colônias inglesas, de Indirect Rule, apesar de não possuírem uma configuração suficientemente forte para que possamos afirmar com convicção que as eleições e o pluralismo são melhores em países que foram colonizados pela Inglaterra. Ainda assim, podemos visualizar — embora timidamente - uma percepção de que as ex-colônias de Direct Rule apresentam um desempenho acentuadamente pior a esse respeito.

O próximo critério considerado pelo índice é o funcionamento do governo. É bastante óbvio que, para se ter sucesso, um regime democrático precisa atender as necessidades dos cidadãos; caso contrário, estes deixarão de acreditar na democracia como a melhor forma de governo (MOISÉS; CARNEIRO, 2008; DEL PORTO, 2016). A legitimidade da democracia perante os cidadãos passa pelo bom funcionamento do governo e, por isso, o Democracy Index considera este critério na formação de seu ranking final. Os resultados estão expostos na tabela a seguir: 
TABELA 5

\begin{tabular}{|c|c|c|c|c|}
\hline \multirow{2}{*}{$\begin{array}{c}\text { Classificação Democracy Index } \\
\text { funcionamento do governo }\end{array}$} & \multicolumn{3}{c|}{ Modelo de administração colonial (\%) } \\
\cline { 2 - 4 } Total & Total & Indirect Rule & Direct Rule \\
\hline \multicolumn{2}{|c|}{} & $\mathbf{9 5}$ & $\mathbf{3 8}$ & $\mathbf{5 7}$ \\
\hline $\begin{array}{c}\text { Democracia } \\
\text { completa }\end{array}$ & $\mathbf{8} \leq \mathbf{s} \leq \mathbf{1 0}$ & 6 & $4,2 \%$ & $2,1 \%$ \\
\hline $\begin{array}{c}\text { Democracia } \\
\text { defeituosa }\end{array}$ & $\mathbf{6} \leq \mathbf{s}<\mathbf{8}$ & 20 & $9,4 \%$ & $11,5 \%$ \\
\hline $\begin{array}{c}\text { Regime } \\
\text { híbrido }\end{array}$ & $\mathbf{4} \leq \mathbf{s}<\mathbf{6}$ & 26 & $12,6 \%$ & $14,7 \%$ \\
\hline $\begin{array}{c}\text { Regime } \\
\text { autoritário }\end{array}$ & $\mathbf{0} \leq \mathbf{s}<\mathbf{4}$ & 43 & $13,6 \%$ & $31,5 \%$ \\
\hline
\end{tabular}

FONTE: Adaptado de THE ECONOMIST (2016).

Continuamos tendo problemas quanto às democracias completas, ou seja, àqueles países que obtiveram notas entre 8 e 10, pois estes são pouquíssimos. Novamente, $4,2 \%$ dos países que foram ex-colônias de Indirect Rule obtiveram as melhores notas, contra 2,1\% dos países de Direct Rule. Ainda, o detalhe que mais chama a atenção está na configuração das piores notas: enquanto apenas 13,6\% das colônias de Indirect Rule obtiveram notas de 0 a 4, isso ocorreu com 31,5\% das colônias de Direct Rule. O dado repete as constatações anteriores: embora não seja possível dizer que as colônias inglesas, de Indirect Rule, são democracias melhores, é notável a dificuldade maior dos países que foram colônias de Direct Rule. Em termos de números, isso significa que 30 ex-colônias das 57 consideradas de Direct Rule têm um desempenho considerado péssimo em termos de funcionamento do governo. Já dos 38 países que foram colônias de Indirect Rule, 25 obtiveram notas de 40 a 10 - ou seja, apenas 13 configuram um péssimo desempenho.

O terceiro critério levado em conta pelo índice é a participação política, assunto este recorrente dentro da Ciência Política como um todo, englobando um conjunto riquíssimo de trabalhos, sejam brasileiros ou estrangeiros — como os de Dallari (1983) e Dagnino (2004). Acredita-se que quanto mais a população participar da política, maior será a qualidade da democracia, enquanto onde o cidadão resume sua atuação política ao ato de votar, a qualidade democrática despenca. Os dados estão expostos na tabela abaixo:

TABELA 6

\begin{tabular}{|c|c|c|c|c|}
\hline \multirow{2}{*}{\multicolumn{2}{|c|}{$\begin{array}{c}\text { Classificação Democracy Index - } \\
\text { participação política }\end{array}$}} & \multicolumn{3}{|c|}{ Modelo de administração colonial (\%) } \\
\hline & & Total & Indirect Rule & Direct Rule \\
\hline \multicolumn{2}{|c|}{ Total } & 95 & 38 & 57 \\
\hline $\begin{array}{c}\text { Democracia } \\
\text { completa }\end{array}$ & $8 \leq \mathrm{s} \leq \mathbf{1 0}$ & 2 & $2,1 \%$ & - \\
\hline $\begin{array}{l}\text { Democracia } \\
\text { defeituosa }\end{array}$ & $6 \leq s<8$ & 23 & $14,7 \%$ & $9,4 \%$ \\
\hline
\end{tabular}


ZALAMENA, J. C. M. Colonização e qualidade democrática: apontamentos com base no democracy index

\begin{tabular}{|c|c|c|c|c|}
\hline $\begin{array}{c}\text { Regime } \\
\text { híbrido }\end{array}$ & $\mathbf{4} \leq \mathbf{s}<\mathbf{6}$ & 33 & $8,4 \%$ & $26,3 \%$ \\
\hline $\begin{array}{c}\text { Regime } \\
\text { autoritário }\end{array}$ & $\mathbf{0} \leq \mathbf{s}<\mathbf{4}$ & 37 & $14,7 \%$ & $24,2 \%$ \\
\hline
\end{tabular}

FONTE: Adaptado de THE ECONOMIST (2016).

A participação política é um dado cujo desempenho é insatisfatório na maioria dos casos. Apenas 2,1\% dos países obtiveram notas de 8 a 10 , que equivalem a "democracia completa" no ranking, e ambos são ex-colônias inglesas de Indirect Rule. Percebemos, nesse caso, que, dos 95 países testados, 37 possuem um péssimo desempenho, com notas menores que 4. Em termos da classificação em Indirect e Direct Rule, temos dados pouco conclusivos: os únicos dois países com notas muito altas são ex-colônias de Indirect Rule e 14,7\% dos países de Indirect Rule obtiveram notas entre 6 e 8, mas o mesmo percentual obteve notas menores que 4. No caso dos países de Direct Rule, nenhum recebeu notas consideradas altas no quesito participação política, e a maioria deles, $26,3 \%$, ficou com notas entre 4 e 6 . Dos países de Direct Rule, 24,2\% obteve desempenho baixíssimo.

A cultura política é o quarto critério analisado pelo Democracy Index. Para essa corrente de pensamento dentro da Ciência Política, a qualidade da democracia está intimamente ligada ao conjunto de valores, atitudes, normas, crenças e hábitos compartilhados pelos membros de uma sociedade (LENA JUNIOR, 2012). Os dados obtidos na análise estão expostos na tabela a seguir:

TABELA 7

\begin{tabular}{|c|c|c|c|c|}
\hline \multirow{2}{*}{$\begin{array}{c}\text { Classificação Democracy Index - } \\
\text { cultura politica }\end{array}$} & \multicolumn{3}{c|}{ Modelo de administração colonial (\%) } \\
\cline { 2 - 4 } Total & Total & Indirect Rule & Direct Rule \\
\hline \multicolumn{2}{|c|}{} & $\mathbf{9 5}$ & $\mathbf{3 8}$ & $\mathbf{5 7}$ \\
\hline $\begin{array}{c}\text { Democracia } \\
\text { completa }\end{array}$ & $\mathbf{8} \leq \mathbf{s} \leq \mathbf{1 0}$ & 5 & $5,2 \%$ & - \\
\hline $\begin{array}{c}\text { Democracia } \\
\text { defeituosa }\end{array}$ & $\mathbf{6} \leq \mathbf{s}<\mathbf{8}$ & 25 & $12,6 \%$ & $13,6 \%$ \\
\hline $\begin{array}{c}\text { Regime } \\
\text { híbrido }\end{array}$ & $\mathbf{4} \leq \mathbf{s}<\mathbf{6}$ & 52 & $18,9 \%$ & $35,7 \%$ \\
\hline $\begin{array}{c}\text { Regime } \\
\text { autoritário }\end{array}$ & $\mathbf{0} \leq \mathbf{s}<\mathbf{4}$ & 13 & $3,1 \%$ & $10,5 \%$ \\
\hline
\end{tabular}

FONTE: Adaptado de THE ECONOMIST (2016).

Em termos de cultura política, percebemos que, dos países que receberam as notas mais altas (8 a 10), todos são ex-colônias de Indirect Rule (5,2\%). Esse é o único dado que pode apresentar uma questão interessante, mas não é suficiente para estabelecer um padrão. Porém, dos países de Indirect Rule, apenas 3,1\% obteve as piores notas. Logicamente, a maioria deles ficou com notas entre 4 e 8 , o que significa que, no que diz respeito a esse 
critério, os países de Indirect Rule ficaram dentro de um intervalo de notas que pode qualificar seus regimes como democracias, embora defeituosas. Já os países de Direct Rule não obtiveram notas altas. A maioria deles também ficou posicionada entre notas de 4 a 8 e, nesse caso, um percentual um pouco maior (em relação às ex-colônias inglesas), de 10,5\%, teve notas menores que 4, consideradas muito baixas e equivalentes a regimes autoritários. Temos um quadro geral que nos diz que tanto ex-colônias de Indirect quanto de Direct Rule possuem desempenhos médios, com notas entre 4 e 8 , no quesito da cultura política.

O quinto e último critério considerado pelo Democracy Index diz respeito às liberdades civis. Esse princípio - que pode ser encontrado em vários textos de acordos internacionais e, inclusive, na Carta da ONU — é considerado pelas definições modernas de democracia como componente vital do regime (DAHL, 1997). De forma simplista, podemos conceituar as liberdades civis como o conjunto de direitos do indivíduo, que modera a capacidade do Estado de interferir na vida do cidadão (BOBBIO, 2004). Sem liberdades de, por exemplo, expressão, imprensa, religião, reunião e associação e acesso à justiça, a democracia pode ser considerada "aleijada".

TABELA 8

\begin{tabular}{|c|c|c|c|c|}
\hline \multirow{2}{*}{$\begin{array}{c}\text { Classificação Democracy Index } \\
\text { Liberdades Civis }\end{array}$} & \multicolumn{3}{c|}{ Modelo de administração colonial (\%) } \\
\cline { 2 - 4 } Total & Total & Indirect Rule & Direct Rule \\
\hline \multicolumn{2}{|c|}{} & $\mathbf{9 5}$ & $\mathbf{3 8}$ & $\mathbf{5 7}$ \\
\hline $\begin{array}{c}\text { Democracia } \\
\text { completa }\end{array}$ & $\mathbf{8} \leq \mathbf{s} \leq \mathbf{1 0}$ & 21 & $11,5 \%$ & $10,5 \%$ \\
\hline $\begin{array}{c}\text { Democracia } \\
\text { defeituosa }\end{array}$ & $\mathbf{6} \leq \mathbf{s}<\mathbf{8}$ & 22 & $7,3 \%$ & $15,7 \%$ \\
\hline $\begin{array}{c}\text { Regime } \\
\text { híbrido }\end{array}$ & $\mathbf{4} \leq \mathbf{s}<\mathbf{6}$ & 22 & $11.5 \%$ & $11,5 \%$ \\
\hline $\begin{array}{c}\text { Regime } \\
\text { autoritário }\end{array}$ & $\mathbf{0} \leq \mathbf{s}<\mathbf{4}$ & 30 & $9,4 \%$ & $22,1 \%$ \\
\hline
\end{tabular}

FONTE: Adaptado de THE ECONOMIST (2016).

No caso das liberdades civis, o número de países com nota entre 8 e 10, equivalentes ao esperado de uma democracia completa — segundo a metodologia do índice —, foi bem mais robusto: 21 países obtiveram notas altas. Nesse caso, 11,5\% dos países com notas altas são de Indirect Rule, ao lado de 10,5\% de Direct Rule (apresentando-se, assim, um desempenho praticamente idêntico entre as duas modalidades). Novamente, o que chama a atenção são os piores resultados: dos países que receberam notas muito baixas - menores que 4 - 22,1\% são ex-colônias de Direct Rule, enquanto apenas 9,4\% são de Indirect Rule. Os demais países, tanto de Indirect quanto de Direct Rule, ficaram com notas intermediárias. 
ZALAMENA, J. C. M. Colonização e qualidade democrática: apontamentos com base no democracy index

Percebemos claramente que os países divergem muito conforme os critérios de análise adotados. Países com notas altas em determinado critério podem se achar com desempenho muito baixo em outros. Por isso, caso o Democracy Index considerasse - de acordo com teorias minimalistas —, por exemplo, apenas o processo eleitoral como critério de avaliação (assim como qualquer outro dos quatro critérios restantes), o resultado do índice seria muito diferente. Há países onde o processo eleitoral existe, mas não é livre, justo ou periódico, o que gera notas baixas, assim como temos exemplos de países cujas notas são altas no que diz respeito às eleições e ao funcionamento do governo, mas extremamente baixas no que diz respeito à participação política, por exemplo. Apenas as democracias consideradas completas tiveram notas de 8 a 10 em todos os quesitos, e estas são raríssimas.

Dos países colonizados, os mais problemáticos quanto à manutenção das democracias estão localizados justamente no continente africano. Muitos outros fatores além da colonização explicam a situação complicada da África quanto aos regimes autoritários, tais como suas condições geográficas e econômicas, as rivalidades entre diferentes etnias agrupadas no mesmo território, a pobreza, a fome, as guerras prolongadas, os conflitos de diversos tipos, os golpes de estado e uma série de problemas sociais que praticamente inviabilizam o próprio pensamento democrático.

Infelizmente, os limites deste trabalho inviabilizam uma análise mais aprofundada a esse respeito. Porém, já é suficiente para apresentar algumas modestas considerações, quais sejam: 1) o modelo de administração colonial de Indirect Rule criou um ambiente favorável para a implementação e consolidação da democracia, o que não garante que isso acontecerá de fato, uma vez que o sucesso da democracia possui muitos outros fatores determinantes e explicativos; 2) os dados sugerem, sutilmente, que países ingleses administrados através do Indirect Rule possuem uma tímida, mas perceptível, vantagem em seu desempenho democrático; e 3) os países colonizados pela França, Portugal, Bélgica, Espanha, Itália e Holanda, cujo modelo de administração foi, em termos gerais, de Direct Rule, alicerçaram suas nações em um legado que não favorece o regime democrático e, por isso, apresentam maiores dificuldades para implementar e consolidar a democracia. A democracia, portanto, pode não ser nitidamente melhor nos países colonizados através do modelo de Indirect Rule, mas estes podem possuir maior potencialidade para chegarem perto de um modelo de democracia ideal. ${ }^{9}$

\footnotetext{
${ }^{9}$ De acordo com a concepção teórica de "democracia ideal" desenvolvida pelos autores mencionados na primeira parte do trabalho, com notável destaque para Dahl (1997).
} 


\section{CONSIDERAÇÕES FINAIS}

A Europa não poupou esforços para dominar praticamente o mundo todo desde que sua população começou a viajar para outros continentes. O continente americano foi dominado ainda no século XVI, enquanto o continente africano foi fatiado e dividido durante a Conferência de Berlim e praticamente todo tomado e explorado por europeus desde o período imperialista do final do século XIX até o pós-Segunda Guerra Mundial. Esse processo de colonização, dominação e exploração deixou inegáveis legados para as ex-colônias, cada uma com suas peculiaridades ligadas ao período colonial. A influência política, a esse respeito, não foi diferente, pois a colonização deixou heranças no comportamento político dessas nações, especialmente no que tange à consolidação e ao sucesso de suas tentativas democráticas.

As democracias são sistemas extremamente heterogêneos e há uma notável dificuldade de se encontrar padrões para sua consolidação, sobrevivência e qualidade. O quão democrático é um regime é algo difícil de se medir e não há consenso sobre como fazer isso. Os próprios conceitos de democracia são frequentemente contestados e o debate de teóricos e políticos que criam teses e concepções sobre ela sobrevive há séculos. Ainda, os conceitos de Indirect e Direct Rule têm seus limites de aplicação, uma vez que nem sempre a mesma potência empregou modelos de administração colonial idênticos em todas as suas colônias.

Tendo em mente as principais limitações deste trabalho — devidas ao fato de as excolônias muitas vezes terem sido administradas por uma mesma potência, mas com graus diferentes de Indirect ou de Direct Rule, e de o Democracy Index não chegar a configurar-se como um completo e acabado índice para mensurar a democracia -, compreende-se que o fator colonização/modelo de colonização não é suficiente para explicar o desempenho democrático de um país. Para que a nossa hipótese fosse comprovada com força total, seria necessário que mais países de Indirect Rule estivessem elencados como democracias completas, o que não ocorreu.

Conforme os dados elucidaram, não há garantia nenhuma de que colônias administradas pelo modelo de Indirect Rule se tornarão nações democráticas melhores. Porém, percebe-se que o modelo de Direct Rule gerou uma quantidade bem maior de regimes autoritários e de países com problemas de operacionalização quanto ao processo eleitoral, ao pluralismo, ao funcionamento do governo, à participação política, à cultura política e às liberdades civis. Pode-se sugerir, com base nisso, que o modelo de Indirect Rule criou condições favoráveis ao desenvolvimento da democracia, enquanto o Direct Rule gerou 
ZALAMENA, J. C. M. Colonização e qualidade democrática: apontamentos com base no democracy index

heranças complicadas que são entraves a ela. Isoladamente, nenhum fator é determinante do sucesso ou insucesso de uma democracia, mas eles têm influência num contexto macro da consolidação democrática.

Temos um conjunto de dados quanto aos cinco critérios do Democracy Index muito suscetível a várias interpretações e que não constitui padrões verificáveis. O único padrão detectável é o de que a maioria dos países que obtiveram notas baixas nesses critérios é formada por ex-colônias de Direct Rule. Assim, podemos entender - com muita cautela que o modelo de Direct Rule gerou países com dificuldades de se autogovernar e de construir uma democracia de qualidade, nos vários aspectos que a compõem — com, evidentemente, a notável exceção do Uruguai, que, dentre os países de Direct Rule, é o único considerado pelo índice como uma democracia completa.

É evidente que outros estudos mais profundos e complexos em torno da comparação entre o fator "colonização" e o fator "qualidade democrática" são imensamente necessários, incluindo-se neles aspectos negligenciados pelo Democracy Index (como os critérios econômicos) e, também, outros índices de mensuração da democracia (como aqueles divulgados pela "Freedom House" e o Democracy Ranking, elaborado pela organização austríaca Democracy Ranking Association). Ainda assim, esperamos que este trabalho possa sintetizar o desempenho democrático das ex-colônias em relação ao Democracy Index e, além disso, abrir caminho para outros trabalhos semelhantes que possam ajudar a elucidar a relação entre a colonização e a democracia.

\section{REFERÊNCIAS}

ACEMOGLU, D.; JOHNSON, S.; ROBINSON, J. The Colonial Origins of Comparative Development: an Empirical Investigation. The American Economic Review, v. 91, n. 5, p. 1369-1401, 2001. Disponível em <http://goo.gl/IXgLcw> Acesso em 21 de novembro de 2017.

Reversal of Fortune: Geography and Institutions in the Making of the Modern World Income Distribution. The Quarterly Journal of Economics, v. 117, n. 4, p. 1231-1294, Jan. 2002. Disponível em: <http://goo.gl/HLqzDl> Acesso em 12 de novembro de 2017.

AKPAN, Monday B. A Etiópia e a Libéria, 1914-1935: dois Estados africanos independentes na era colonial. In: BOAHEN, Albert Adu. História Geral da África - Volume VII. Brasília: Unesco, 2010a.

Libéria e Etiópia, 1880-1914: a sobrevivência de dois Estados africanos. In: BOAHEN, Albert Adu. História Geral da África - Volume VII. Brasília: Unesco, 2010b. 
ALMEIDA, P. R. de. Falácias acadêmicas, 14: o mito do colonialismo como causador de subdesenvolvimento. Revista Espaço Acadêmico, v. 10, n. 109, p. 12-26, 2010.

ARANHA, C. Libéria: um sonho americano. Aventuras na História, n. 6, p. 40-45, 2004.

BALDWIN, R. E. Patterns of Development in Newly Settled Regions. The Manchester School, v. 24, n. 2, p. 161-179, 1956. Disponível em: <http://goo.gl/YO05V8> Acesso em 12 de novembro de 2017.

BANERJEE, A. V.; IYER, L. History, Institutions and Economic Performance: the Legacy of Colonial Land Tenure Systems in India. The American Economic Review, v. 95, n. 4, p. 11901213, 2005.

BARKER, A. J. A conquista da Etiópia: sonho de um Império. Rio de Janeiro: Renes, 1979.

BATISTA, M. O poder no Executivo: explicações no presidencialismo, parlamentarismo e presidencialismo de coalizão. Revista Sociologia Política, Curitiba, v. 24, n. 57, mar. 2016. Disponível em: <http://www.scielo.br/pdf/rsocp/v24n57/0104-4478-rsocp-24-57-0127.pdf>. Acesso em 22 de novembro de 2017.

BOBBIO, N. Era dos direitos. Rio de Janeiro: Elsevier Brasil, 2004.

CORREA, S. M. História, memória e colonialismo (alemão) em questão. Anos 90, v. 21, n. 40, 2014.

DAGNINO, E. ¿Sociedade civil, participação e cidadania: de que estamos falando? In: MATO, D.; BENESSAIEH, A. Políticas de ciudadanía y sociedad civil en tiempos de globalización. Caracas: FACES, 2004. p. 95-110.

DAHL, R. A. Poliarquia: participação e oposição. São Paulo: Edusp, 1997.

Transitions to Democracy. Trabalho apresentado no Simpósio Voices of Democracy, Dayton, 1990.

DALLARI, D. A. O que é participação política. São Paulo: Brasiliense, 1983.

DEL PORTO, F. B. Satisfação com a democracia e avaliação de governo: fenômenos distintos? Trabalho apresentado no 40. Encontro Anual da ANPOCS, Caxambu, out. 2016. Disponível em: <http://www.anpocs.com/index.php/papers-40-encontro/st-10/st06-8/10180satisfacao-com-a-democracia-e-avaliacao-de-governo-fenomenos-distintos/file> Acesso em 05 de novembro de 2017.

DIAMOND, L.; LINZ, J. Politics, Democracy and Society in Latin America. In: DIAMOND, L.; LINZ, J.; LIPSET, S. M. (Ed.). Democracy in Developing Countries: Latin America. Boulder: Lynne Rienner, 1989.

DOYLE, Michael W. Empires. Ithaca, N.Y.: Cornell University Press, 1986.

ENGERMAN, S.; SOKOLOFF, K. Factor Endowments, Institutions and Differential Paths of Growth among New World Economies: a View from Economic Historians of the United 
ZALAMENA, J. C. M. Colonização e qualidade democrática: apontamentos com base no democracy index

States. In: HABER, S. How Latin America Fell Behind. Stanford, CA: Stanford University Press, 1997.

GERRING, J. et al. An Institutional Theory of Direct and Indirect Rule. World Politics, v. 63, n. 3, p. 377-433, 2011. Disponível em: <http://blogs.bu.edu/jgerring/files/2013/06/Indirectrule.pdf>. Acesso em 22 de Agosto de 2017.

HEEREN, A. H. L. Handbuch der Geschichte des europäischen Staatensystems und seiner Colonien: von der Entdeckung beyder Indien bis zur Errichtung des Französichen Kaiserthrons. Gottingen: M. Lechner, 1817.

HIRSCHMANN, A. The Social and Political Matrix of Inflation: Elaborations on the Latin American Experience. In: . Essays in Trespassing: Economics to Politics and beyond. New York: Cambridge University Press, 1981. p. 177-207.

HUNTINGTON, S. A ordem política nas sociedades em mudança. Rio de Janeiro: Forense Universitária; São Paulo: Edusp, 1975.

IYER, L. Direct versus Indirect Colonial Rule in India: Long-term Consequences. Review of Economics and Statistics, v. 92, n. 4, p. 693-713, 2010. Disponível em: <http://www.hbs.edu/faculty/Publication\%20Files/05-041_1feff996-f50e-4e5a-b057e0119cd19a62.pdf>. Acesso em 29 de setembro de 2017.

KEKIC, L. The Economist Intelligence Unit's Index of Democracy. 2006. Disponível em: $<$ http://www.economist.com/media/pdf/DEMOCRACY_INDEX_2007_v3.pdf>.

LACOSTE, Y.; RAJAGOPALAN, K. Por uma abordagem geopolítica da difusão do inglês. LACOSTE, Y.; RAJAGOPALAN, K.; MARCIONILO, M. A geopolítica do inglês. São Paulo: Parábola Editorial, 2005. p. 7-11. Disponível em: <http://www.educadores.diaadia.pr.gov.br/arquivos/File/2010/artigos_teses/Ingles/lacoste.pdf>. Acesso em 22 de novembro de 2017.

LENA JUNIOR, H. de. Uma reflexão acerca do conceito de cultura política. Revista Confluências, Niterói, v. 12, n. 1, p. 155-176, out. 2012. Disponível em: <www.confluencias.uff.br/index.php/confluencias/article/download/258/132> Acesso em 12 de novembro de 2017.

LEROY-BEAULIEU, P. De la colonisation chez les peuples modernes. Paris: Guillaumin, 1902.

LINZ, J. The Perils of Presidencialism. Journal of Democracy, v. 1, n. 1, p. 51-69, 1990.

The Virtues of Parliamentarism. Journal of Democracyi, v. 1, n. 4, p. 84-91, 1990.

LIPSET, S. M. Some Social Requisites of Democracy: Economic Developmet and Political Legitimacy. American Political Science Review, v. 53, 1959.

MABEKO-TALI, J. Considerações sobre o despotismo colonial e a gestão centralizada da violência no Império colonial francês. Varia Historia, v. 29, n. 51, p. 745-770, 2013. 
MAINWARING, S. Presidentialism in Latin America. Latin American Research Review, v. 25, p. 157-179, 1990.

. Presidentialism, Multipartism and Democracy: the Difficult Combination. Comparative Political Studies, v. 26, 1993.

MANIN, B.; PRZEWORSKI, A.; STOKES, S. C. Eleições e representação. Lua Nova, n. 67, p. 105-138, 2006.

MELLO, F. C. Socialismo, modernidade e identidade regional em Mariátegui, Senghor e Nkrumah. Revista Brasileira de Ciências Sociais, v. 31, n. 92, out. 2016. Disponível em: $<$ http://www.scielo.br/pdf/rbcsoc/v31n92/0102-6909-rbcsoc-3192132016.pdf>. Acesso em 22 de novembro de 2017.

MOISÉS, J. A.; CARNEIRO, G. P. Democracia, desconfiança política e insatisfação com o regime: o caso do Brasil. Revista Opinião Pública, Campinas, v. 14, n. 1, jun. 2008. Disponível em: <http://www.scielo.br/scielo.php?script=sci_arttext\&pid=S0104$62762008000100001>$. Acesso em 2 de agosto de 2017.

MONASTERIO, L.; EHRL, P. Colônias de Povoamento versus Colônia de Exploração: de Heeren a Acemoglu. Brasília: Ipea, 2015. Disponível em: $<$ http://ipea.gov.br/agencia/images/stories/PDFs/TDs/td_2119.pdf>. Acesso em 15 de agosto 2017.

MUNANGA, K. Algumas considerações sobre "raça", ação afirmativa e identidade negra no Brasil: fundamentos antropológicos. Revista USP, São Paulo, n. 68, p. 46-57, dez./fev. 20052006. Disponível em: <https://www.revistas.usp.br/revusp/article/viewFile/13482/15300>. Acesso em 20 de Agosto de 2017.

NORTH, D. C. Location Theory and Regional Economic Growth. The Journal of Political Economy, p. 243-258, 1959. Disponível em: <http://goo.gl/GAuvpn> Acesso em 12 de novembro de 2017.

O'DONNEL, G Modernization and Bureaucratic-Authoritarianism: Studies in South American Politics. Berkeley: University of California, 1973.

PÁEZ, P. et al. História da Etiópia. Livraria Civilização: Porto, 1945.

PASSETTI, Gabriel. Os britânicos e seu império: debates e novos campos da historiografia do período vitoriano. História (São Paulo), v. 35, 2016. Disponível em: http://www.scielo.br/pdf/his/v35/0101-9074-his-35-e77.pdf Acesso em 14 de novembro de 2017.

PINI, A. M. A descolonização da Namíbia: as negociações. 100 f. Dissertação (Mestrado em Relações Internacionais) - Universidade de Brasília, Brasília, 2014.

PRADO JUNIOR, C. História econômica do Brasil. São Paulo: Brasiliense, 1957. Disponível em: <http://goo.gl/XpZy6A> Acesso em 07 de novembro de 2017. 
ZALAMENA, J. C. M. Colonização e qualidade democrática: apontamentos com base no democracy index

PRZEWORSKI, Adam. Minimalist conception of democracy: a defense. Democracy's value, v. 23, 1999.

PRZEWORSKI, A. et al. O que mantém as democracias. Lua Nova, v. 40, n. 41, p. 113-135, 1997.

ROSCHER, W. G. F. Kolonien, Kolonialpolitik und Auswanderung. Leipzig: C. F. Winter, 1856.

SCHUMPETER, J. Capitalismo, socialismo e democracia. Rio de Janeiro: Zahar Editora, 1984.

SOUZA, J. P. A. Entre o sentido da colonização e o arcaísmo como projeto: a superação de um dilema através do conceito de capital escravista-mercantil. Estudos Econômicos, São Paulo, v. 38, n. 1, jan./mar. 2008. Disponível em: $<$ http://www.scielo.br/pdf/ee/v38n1/08.pdf>. Acesso em 22 de agosto de 2017.

STEPAN, A. Parlamentarismo x presidencialismo no mundo moderno: revisão de um debate atual. Revista Estudos Avançados, São Paulo, v. 4, n. 8, jan./abr. 1990. Disponível em: <http://www.scielo.br/pdf/ea/v4n8/v4n8a07.pdf> Acesso em 22 de novembro de 2017.

THE ECONOMIST. Democracy Index 2016: Revenge of the "Deplorables". 2016. Disponível em: <http://felipesahagun.es/wp-content/uploads/2017/01/Democracy-Index2016.pdf> Acesso em 12 de novembro de 2017.

VALENZUELA, A. A opção parlamentarista para a América Latina. Lua Nova, São Paulo, n. 24, set. 1991. Disponível em: <http://www.scielo.br/pdf/ln/n24/a04n24.pdf>. Acesso em 22 de novembro de 2017 